\title{
D.O.M. - UM JOGO SOBRE FUNÇÕES QUADRÁTICAS: ENTRE A EDUCAÇÃO E O ENTRETENIMENTO.
}

\author{
William Santos, PPGMCTI Faculdade Senai Cimatec - Salvador/Ba, \\ william_tenor@yahoo.com.br \\ Lynn Alves, PPGMCTI Faculdade Senai Cimatec e UNEB - Salvador/Ba, \\ lynnalves@gmail.com
}

Resumo. As últimas avaliações de desempenho estudantil realizadas no Brasil, como a Prova Brasil (2015) e o PISA (2015)-Programa Internacional de Avaliação de Estudantes, apontam a existência de um grande déficit na aprendizagem dos conteúdos de Matemática. Como tem ocorrido em países da Europa e nos Estados Unidos, a adoção de jogos digitais para mediar a aprendizagem tem contribuído para a melhoria destes índices educacionais. Cremos que estes ambientes de aprendizagem podem contribuir de forma significativa para a aprendizagem matemática, pois ao interagir com eles, é possível testar e simular hipóteses, contextualizando e aplicando conceitos de um determinado assunto. Para tanto, o objetivo deste trabalho é apresentar o projeto e o desenvolvimento de um jogo digital ocorrido durante um mestrado em modelagem computacional, de gênero plataforma que cadencia a aprendizagem sobre funções quadráticas e entretenimento.

Palavras-Chave: Jogos Digitais, Matemática, Aprendizagem

\section{D.O.M. - A GAME ON QUADRATIC FUNCTIONS: BETWEEN EDUCATION AND ENTERTAINMENT.}

Abstract. The latest evaluations of student performance in Brazil, such as Prova Brasil (2015) and PISA (2015) - International Student Assessment Program, show a great deficit in the learning of Math contents. It has been noted in both European countries and in the United States that the use of digital games to support learning has contributed to the improvement of educational indexes. It is believed these learning environments can contribute significantly to mathematical learning because interaction with them allows testing and simulation of hypotheses through contextualization and application of ad hoc concepts. Therefore, this paper aims at presenting the design and the development of a digital game, which has led to a master's degree in computer modeling, a kind of platform that harmonize both learning of quadratic functions and entertainment.

Keywords: Digital Games, Math, Learning

\section{Introdução}

Em dezembro de 2016, o relatório do PISA apontou mais uma vez que a aprendizagem matemática no Brasil está abaixo da média, considerando o critério da Organização para a Cooperação e Desenvolvimento Econômico (OCDE). Pela análise dos resultados desta avaliação, ocorrida no ano de 2015, 44,1\% dos estudantes brasileiros estão abaixo do nível de 
aprendizagem que é considerado adequado em leitura, matemática e ciências.

$\mathrm{Na}$ tentativa de melhorar seus índices nessas avaliações, países da Europa e da América do Norte tem investido em jogos digitais como ambientes mediadores do processo de ensino, e tal adoção vem apresentando bons resultados. Alguns deles são apresentados neste artigo, como também a indicação de jogos digitais integrados a estas experiências, em especial o jogo brasileiro D.O.M., que foi desenvolvido para mediar o ensino das funções quadráticas, e tem o intuito de contribuir para a melhoria dos índices brasileiros quanto a aprendizagem da matemática.

Assim, este artigo tem o objetivo de discutir estas experiências pedagógicas mediadas pelo jogos digitais e suas contribuições no desenvolvimento do D.O.M., um game para mediar a aprendizagem das funções quadráticas.

\section{O Cenário da Aprendizagem Matemática no Brasil}

Tomando como base as avaliações nacionais e internacionais sobre a aprendizagem matemática, observa-se a necessidade da adoção de novas metodologias que possam contribuir para a melhoria do ensino brasileiro e consequentemente para o aumento nos índices que regulam estes fins.

Analisando as avaliações do PISA que se referem a aprendizagem matemática, vê-se que ao longo dos anos a posição do Brasil tem caído, demonstrando que outros países tem se saído melhor e que além de aumentarem suas pontuações, têm conseguido lograr posições mais avançadas neste ranking, fazendo com que o Brasil ocupe atualmente a $65^{\mathrm{a}}$ posição.

Tabela 01 - Brasil no PISA

\begin{tabular}{|c|c|c|c|}
\hline Ano & Posição & País & Pontuação \\
\hline \multirow{2}{*}{2000} & 1 & Holanda & 564 \\
\cline { 2 - 4 } & 42 & Brasil & 334 \\
\hline \multirow{2}{*}{2003} & 1 & China(Hong Kong) & 550 \\
\cline { 2 - 4 } & 41 & Brasil & 356 \\
\hline \multirow{2}{*}{2006} & 1 & China (Taiwan) & 549 \\
\cline { 2 - 4 } & 54 & Brasil & 370 \\
\hline \multirow{2}{*}{2009} & 1 & China (Xangai) & 600 \\
\cline { 2 - 4 } & 57 & Brasil & 386 \\
\hline \multirow{2}{*}{2012} & 1 & China (Xangai) & 613 \\
\cline { 2 - 4 } & 58 & Brasil & 391 \\
\hline \multirow{2}{*}{2015} & 1 & Singapura & 564 \\
\cline { 2 - 4 } & 65 & Brasil & 377 \\
\hline
\end{tabular}

No cenário nacional encontramos um perfil similar. Segundo as análises feitas pelo ENEM (Exame Nacional do Ensino Médio), nos anos de 2014 e 2015, das disciplinas avaliadas, Matemática teve a menor média com 473,5 e 467,9 pontos, respectivamente. Outro desempenho baixo é encontrado no IDEB (Índice de Desenvolvimento da Educação Básica), onde nas duas 
últimas avaliações, a meta não foi atingida, como pode ser visto na Tabela 02.

Tabela 02 - Brasil no IDEB

\begin{tabular}{|c|c|c|c|c|}
\hline \multirow{2}{*}{ Anos } & \multicolumn{2}{|c|}{ Ens. Fund. Anos Finais } & \multicolumn{2}{c|}{ Ensino Médio } \\
\cline { 2 - 5 } & Meta & IDEB Observado & Meta & IDEB Observado \\
\hline 2013 & 4,4 & 4,2 & 3,9 & 3,7 \\
\hline 2015 & 4,7 & 4,5 & 4,3 & 3,7 \\
\hline
\end{tabular}

Fonte - SAEB 2015

A mesma situação ocorre quando são analisados os índices da Prova Brasil. Apesar da crescente evolução nos índices das séries iniciais, as séries finais têm mantido o mesmo patamar ao longo dos anos, sem demonstrar grandes avanços, enquanto o ensino médio vem apresentando um decréscimo nestes índices, conforme o Gráfico 01.

\section{Gráfico 01 - Índices da Prova Brasil}
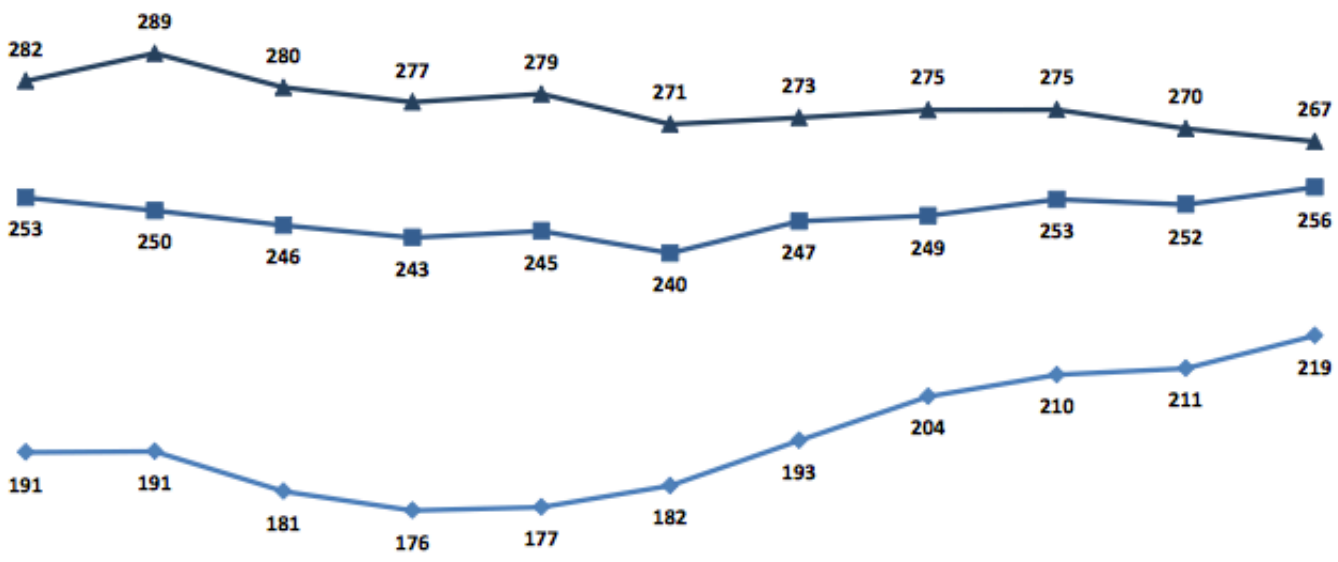

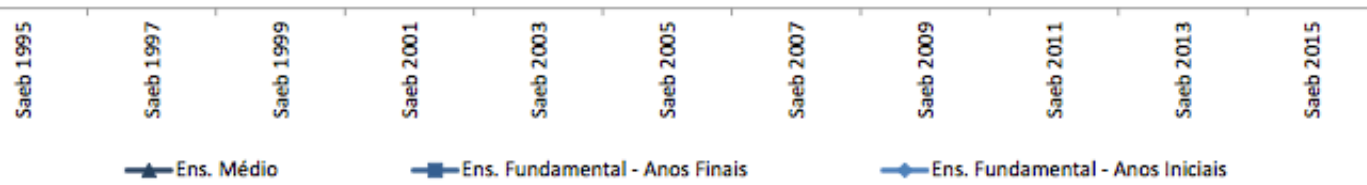

Fonte - SAEB 2015

Todo esse contexto tem evidenciado a grande defasagem em que se encontram os alunos brasileiros quanto a aprendizagem matemática. Em uma tentativa de reverter um quadro similar a este, países como Reino Unido e Estados Unidos têm investido em novas práticas e metodologias através dos jogos digitais, objetivando melhorar a aprendizagem dos seus alunos.

\section{Potencialidades dos Jogos Para o Ensino de Matemática}

Os jogos digitais podem ser utilizados diretamente no processo de ensino aprendizagem trazendo importantes contribuições. Segundo Alves (2008), ao interagir como jogos eletrônicos, as funções cognitivas são intensificadas, permitindo a descoberta de novas formas de conhecimento. 
Com base nos estudos de Gee (2008), os jogos digitais comerciais estabelecem princípios de aprendizagem e alguns deles se relacionam diretamente com a matemática. São eles:

a) Interação - os jogos oferecem um feedback e esta resposta pode permitir ao jogador criar conjecturas e resolver situações-problema que lhe são apresentadas.

b) Produção - aponta o fato dos jogadores assumirem uma postura ativa, executando e decidindo sobre suas futuras ações.

c) Riscos - o tratamento sobre o erro pode ser visto como tentativa de acerto. Dentro de um jogo quando se erra, é possível retornar e refazer o desafio buscando outras alternativas de acerto.

d) Desafio e consolidação - os jogos apresentam uma série de situações-problema que dependem dos conhecimentos prévios estabelecidos nas fases anteriores, atrelados a conhecimentos que eles precisam adquirir ao longo do jogo para conseguir alcançar sua meta.

Analisando estes princípios, vê-se que os mesmos se constituem em torno da resolução de problemas, desafios e conquista de metas. Mas para que esse objetivo seja atingido, os conhecimentos prévios devem ser considerados, promovendo situações nas quais os alunos possam levantar e testar hipóteses para solucionar problemas, construindo um cenário propício para o aprendizado matemático.

Considerando tais perspectivas sobre as potencialidades dos jogos e suas afinidades com a matemática, Mattar (2010) apresenta alguns jogos que têm sido utilizados nos Estados Unidos para o ensino da matemática. (Tabela 03).

Tabela 03 - Alguns games utilizados no ensino da Matemática

\begin{tabular}{|l|l|}
\hline \multicolumn{1}{|c|}{ GAMES } & \multicolumn{1}{c|}{ ENREDO } \\
\hline Dimension M & $\begin{array}{l}\text { É um mundo de jogos imersivos em 3D, que envolve os alunos na } \\
\text { aprendizagem e aplicação da matemática. }\end{array}$ \\
\hline Brain Age & $\begin{array}{l}\text { O jogo contém atividades para estimular o raciocínio, com } \\
\text { problemas matemáticos e de lógica. }\end{array}$ \\
\hline Dream Box & $\begin{array}{l}\text { Game de aventura com dinossauros, piratas onde o gamer } \\
\text { precisa resolver problemas de Matemática para progredir de fase. }\end{array}$ \\
\hline $\begin{array}{l}\text { Lure of } \\
\text { Labirinth }\end{array}$ & $\begin{array}{l}\text { Game para o ensino fundamental que inclui uma série de puzzles } \\
\text { baseados em Matemática onde os alunos trabalham para } \\
\text { encontrar um animal perdido e salvar o mundo de monstros. }\end{array}$ \\
\hline Math City & $\begin{array}{l}\text { Game colaborativo que envolve pais, professores e alunos. } \\
\text { Yu-Gi-Yo }\end{array}$ \\
\hline
\end{tabular}

Fonte: Mattar (2010)

Nesta mesma pesquisa, Mattar (2010) sinaliza que a utilização do jogo Dimension $M$ pelos alunos da cidade de Nova York fez com que o índice de aprovação em matemática passasse de $78 \%$ para $82 \%$, no ano de 2007. 
Outro exemplo desta melhoria ocorreu no Reino Unido. Segundo Rowland (2013), depois de três anos usando a plataforma Mangahigh de jogos digitais, as notas de um exame nacional foram de $55 \%$ para $80 \%$. Esta mesma plataforma vem sendo utilizada em escolas no Brasil como o Sesi Rio e em uma delas foi registrado que as médias em matemática passaram de 5 para 6,7.

Estes dados evidenciam que os jogos digitais, comerciais ou com fins educacionais, podem contribuir para o processo de ensino aprendizagem da matemática, nos levando a acreditar que sua inserção nos programas oficiais de ensino, possam resultar em dados mais positivos da aprendizagem, além de possibilitar que os alunos interajam com tecnologias que já fazem parte do seu cotidiano de forma lúdica e prazerosa.

\section{A Importância do Ensino das Funções}

Nos exames nacionais e internacionais a maior parte das questões se refere aos conhecimentos sobre Álgebra, ramo mais formal da Matemática Pura e que tem aplicações dos conceitos de funções. Segundo Oliveira (2007), o assunto de funções é relatado pelos alunos como o mais difícil, devido a sua transposição e aspectos mais formais do assunto. As suas aplicabilidades são as mais variadas, por exemplo, os conceitos sobre funções quadráticas estão presentes nos faróis de carro, antenas parabólicas, radares, lançamentos de projéteis, etc. Segundo Santos (2014), pode-se enxergar o vasto campo de utilização das funções quadráticas na física, química, biologia, engenharia, nos cálculos de áreas de regiões sob curvas, localização de pontos na esfera terrestre, pontos de nivelamento entre despesas e lucros e outras aspectos importantes no contexto social da população.

Diante do exposto, foram pesquisados jogos digitais disponíveis no mercado que poderiam contribuir com o ensino da Álgebra, mais precisamente no ensino dos assuntos de equação e função do primeiro e segundo grau. Encontramos os seguintes jogos, expressos na Tabela 04.

Tabela 04 - Jogos Disponíveis

\begin{tabular}{|c|c|c|c|}
\hline $\begin{array}{c}\text { Jogo/ } \\
\text { Empresa }\end{array}$ & Assunto & Características & gem do Jogo \\
\hline $\begin{array}{c}\text { Jabara / } \\
\text { Mangahigh }\end{array}$ & $\begin{array}{c}\text { Equação } \\
\text { do } 1^{\circ} \\
\text { Grau }\end{array}$ & $\begin{array}{l}\text { Este jogo permite que o aluno } \\
\text { compreenda a sintaxe e os } \\
\text { procedimentos de resolução de uma } \\
\text { equação do primeiro grau. Neste jogo, } \\
\text { é necessário arrastar com o mouse os } \\
\text { números e as variáveis entre os } \\
\text { termos da equação, simplificando-a até } \\
\text { chegar ao resultado final. Durante as } \\
\text { interações percebe-se que o jogo se } \\
\text { torna repetitivo e desinteressante, pois } \\
\text { as fases acabam se parecendo com } \\
\text { exercícios que ganharam uma versão } \\
\text { digital, onde ao invés do lápis } \\
\text { escrevendo os números e variáveis em } \\
\text { cada termo, se utiliza o mouse } \\
\text { arrastando os mesmos entre os } \\
\text { termos. }\end{array}$ & \\
\hline
\end{tabular}


Este jogo em suas distintas fases apresenta diversas formas fatoradas de equações do segundo grau, relacionando-as com a área de um retângulo, permitindo ao jogador identificar as possíveis representações de uma equação.

The Recks Equação Neste jogo, é necessário por exemplo, Factor / do $2^{\circ}$ Mangahigh Grau representar a equação $x^{2}-5 x+6$ como sendo um retângulo de lados $(x-2)$ e $(x-3)$, formando este retângulo através do arrasto do mouse. Interagindo com o jogo, algumas situações apresentadas permitem a possibilidade de respostas diferentes, viabilizando para o jogador uma maior interação e liberdade, o que faz o jogo se tornar bem interessante.

Este jogo apresenta a relação entre a função matemática e o seu respectivo gráfico, através de pontos pertencentes ao plano cartesiano.

Nele o jogador escolhe uma função e dois pontos cartesianos que fazem parte desta função clicando sobre eles criando uma trajetória. A interação com o jogo mostrou que a mecânica desfavorece a interatividade, já que o jogador só precisa clicar nas respostas que considera certa, porém o fato da necessidade de criação de 2 pontos para validar a função escolhida faz com que o jogador possa refletir sobre sua escolha, melhorando a interatividade no jogo. Mangahigh

do $1^{\circ} \mathrm{e}$

$2^{\circ}$ Grau

Este jogo traz situações-problemas sobre equações ou inequações do primeiro grau, utilizando propriedades da igualdade desigualdade na construção procedimentos para resolvê-las.

Sr. X /

Tamboro
Equação do $1^{\circ}$

Grau
Nele é necessário arrastar os personagens de forma a igualar a equação. Ao interagir com o jogo verificou-se um bom nível de interação para o jogador que tem a liberdade de fazer diversos movimentos com os personagens para conseguir balancear os vagões deixando o fugitivo que representa a varável $\mathrm{x}$, sozinho, como é feito na resolução de uma equação.

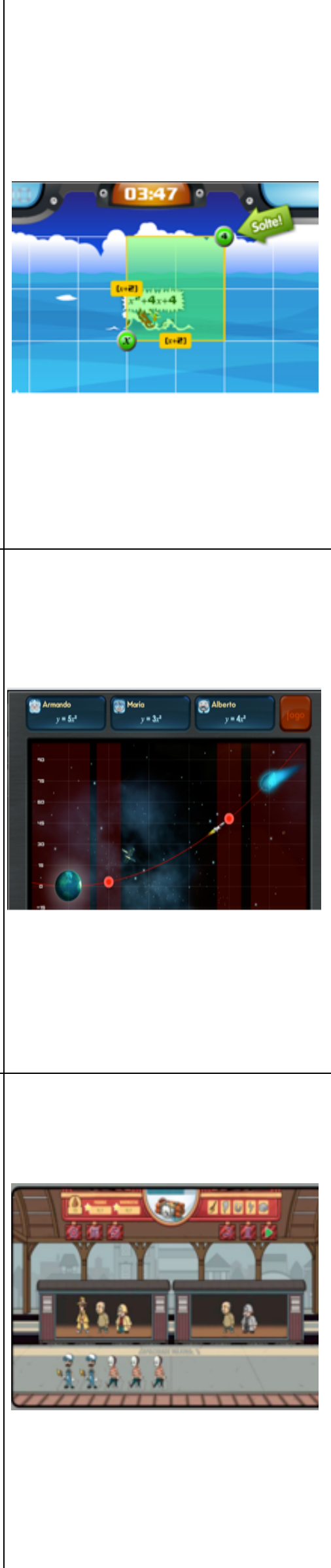




\begin{tabular}{|c|c|c|c|}
\hline $\begin{array}{l}\text { Angry } \\
\text { Birds/ } \\
\text { Rovio }\end{array}$ & $\begin{array}{c}\text { Função } \\
\text { do } 2^{\circ} \\
\text { Grau }\end{array}$ & $\begin{array}{l}\text { Como este jogo não foi desenvolvido } \\
\text { com o intuito educacional, ele } \\
\text { diretamente não se vincula a um } \\
\text { conteúdo específico. Contudo, é } \\
\text { possível visualizar trajetórias } \\
\text { parabólicas, este jogo vem tendo } \\
\text { grande aceitabilidade nas aulas de } \\
\text { função quadrática. As situações do } \\
\text { jogo são transpostas de forma que } \\
\text { possam ser calculados aspectos } \\
\text { referentes as funções quadráticas. }\end{array}$ & in \\
\hline
\end{tabular}

Fonte: Autores

Através da análise e da interação com estes jogos digitais, viu-se que aqueles que foram desenvolvidos com fins educacionais não apresentam preocupações com o entretenimento e a interatividade. Apesar das contribuições que os mesmos apresentam, pois a matemática é evidenciada de forma contextualizada em suas possíveis aplicações, estes artefatos podem ser considerados como jogos casuais simples e se constituem em reproduções animadas de exercícios, que exigem uma interação baseada apenas em cliques com o mouse perdendo um pouco da atratividade de um jogo digital comercial. Em contraponto o Angry Birds se constitui em um fenômeno de entretenimento, mas tem suas limitações no que diz respeito a sua adequação no contexto educacional, já que não fora desenvolvido para estes fins.

$\mathrm{Na}$ tentativa de buscar um ponto de equilíbrio entre entretenimento, ludicidade e aprendizagem de conceitos escolares, aceitamos o desafio de desenvolver um jogo que se constituísse em um espaço diferenciado para aprendizagem das funções quadráticas. O ponto de equilíbrio proposto se consolidou mediante a construção de uma narrativa que favoreceu o engajamento dos alunos, diferenciando-se dos jogos casuais na medida em que aborda habilidades como a flexibilidade cognitiva, planejamento, entre outras.

\section{O Jogo D.O.M.}

Esse ponto de equilíbrio conseguiu ser alcançado durante a pesquisa de mestrado intitulada: (D.O.M.: Um Modelo de Game para a Aprendizagem das Funções Quadráticas no Ensino Médio), vinculada ao Programa de PósGraduação em Modelagem Computacional e Tecnologia Industrial da Faculdade Senai Cimatec - Salvador/Ba.

\subsection{O Projeto}

O jogo D.O.M. foi produzido pela equipe do Centro de Pesquisa e Desenvolvimento Comunidades Virtuais, sediado na Universidade do Estado da Bahia - UNEB e tem em seu portfólio doze jogos desenvolvidos para distintos cenários de aprendizagem.

O desenvolvimento deste jogo teve o financiamento da Secretaria de Educação do Estado da Bahia e vem sendo utilizado nos Centros Juvenis de 
Ciência e Cultura (CJCC), uma iniciativa de educação integral da Secretaria da Educação.

O jogo caracteriza-se pelo gênero plataforma, em 2D com interação através do teclado e mouse, para alunos o $1^{\circ}$ Ano do Ensino Médio e estimula a aprendizagem e aplicação das funções quadráticas. O jogo D.O.M. está disponível para os sistemas operacionais Windows e Linux e com download gratuito no site do Centro de Pesquisas (www.comunidadesvirtuais.pro.br). A sigla D.O.M. faz referência ao domínio de uma função e refere-se também ao Dispositivo Oral Móvel, que é o capacete de inteligência artificial utilizado pelo personagem principal que orienta a resolução dos problemas que são apresentados durante o jogo.

\subsection{O Desenvolvimento}

Apesar de estarmos cientes desde o início do projeto quanto a necessidade de contextualizar o assunto de funções quadráticas, resolvemos percorrer um caminho contrário à sua produção. A prioridade seria um enredo atrativo cuja narrativa pudesse conquistar o jogador e dentro deste contexto, evidenciar o conteúdo matemático, sem que se perdesse a interação e o desejo de jogar. Segundo Mattar (2010), uma das grandes dificuldades no processo de aprendizagem é que a escola separa aprendizagem de prazer, então nosso intuito seria propiciar a interação com um jogo divertido e através dele, mediar a aprendizagem. Tais definições foram subsidiadas pela análise dos jogos indicados na seção 4 e pela nossa imersão no universo dos games.

A narrativa do D.O.M. tem início no ano de 2154. Uma família viaja de férias pelo espaço quando tem sua viagem interrompida, pois um meteorito se choca com a nave que cai em um planeta selvagem e desconhecido. $O$ único integrante da tripulação que se mantém consciente é um jovem de nome GUI, que precisa correr contra o tempo e as ameaças deste planeta inóspito para salvar os outros tripulantes da nave, tendo que recuperar as peças da nave que foram perdidas durante a queda. Então, neste ambiente de aventura e exploração o personagem precisa recuperar as peças da nave espacial. Para conseguir alcançar este objetivo, o jogador administrará informações sobre os conceitos referentes às funções quadráticas que estarão presentes durante os desafios do jogo.

O jogo D.O.M. por ser um jogo com fins educacionais, está sintonizado com as matrizes curriculares nacionais, especialmente as Orientações Curriculares do Ensino médio, que sinaliza:

\footnotetext{
O estudo dessa função - posição do gráfico, coordenadas do ponto de máximo/mínimo, zeros da função - deve ser realizado de forma que o aluno consiga estabelecer as relações entre o "aspecto" do gráfico e os coeficientes de sua expressão algébrica, evitando-se a memorização de regras. (BRASIL, 2006, p.73)
}

Desta forma os conceitos estudados durante o jogo refere-se as relações entre os coeficientes, a posição e o formato do gráfico, como pode ser visto nas Figuras 01 e 02.

Considerando uma função do tipo $y=A x^{2}+B x+C$, o coeficiente $A$ determina se a parábola tem concavidade voltada para cima ou para baixo. 
coeficiente $\mathrm{C}$ determina o ponto onde a parábola corta o eixo $\mathrm{y}$, enquanto $\mathrm{o}$ coeficiente $B$ determina em que quadrante o vértice da parábola estará.
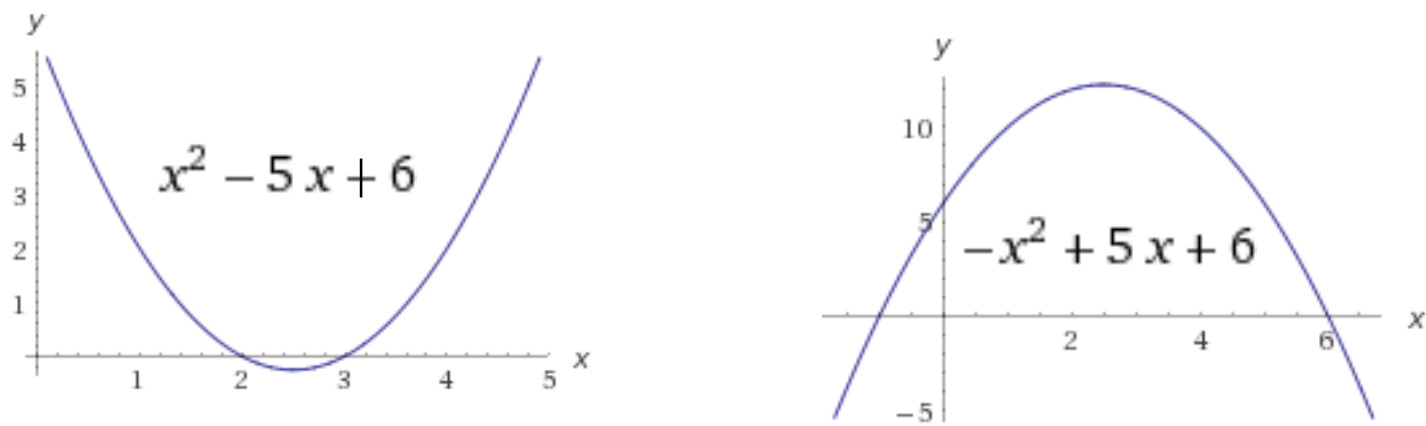

Figura 01: Coeficientes x Posição do Gráfico

Quanto ao formato da parábola, o coeficiente A determina que quanto maior o valor absoluto deste coeficiente, maior será a taxa de variação $a=\frac{\Delta y}{\Delta x}$ a partir do vértice da parábola, o que gera um gráfico mais fechado ou aberto. $O$ coeficiente $B$ determina o posicionamento do vértice da parábola em relação ao eixo y. Alterando os valores deste coeficiente a parábola contorna o centro do plano cartesiano. Já o coeficiente $C$, determina a que distância do eixo x o vértice da parábola estará.

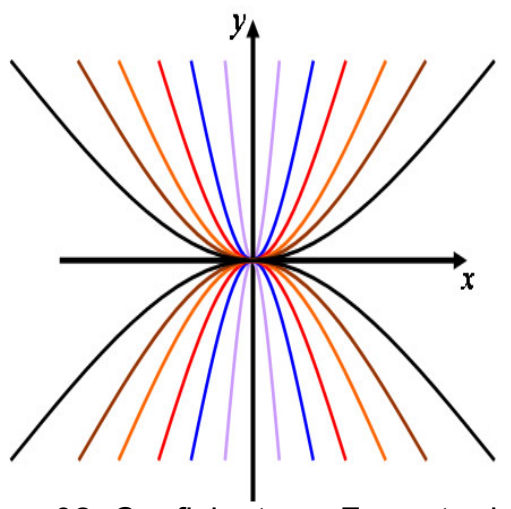

Figura 02: Coeficientes x Formato do Gráfico

\subsection{O Produto Final}

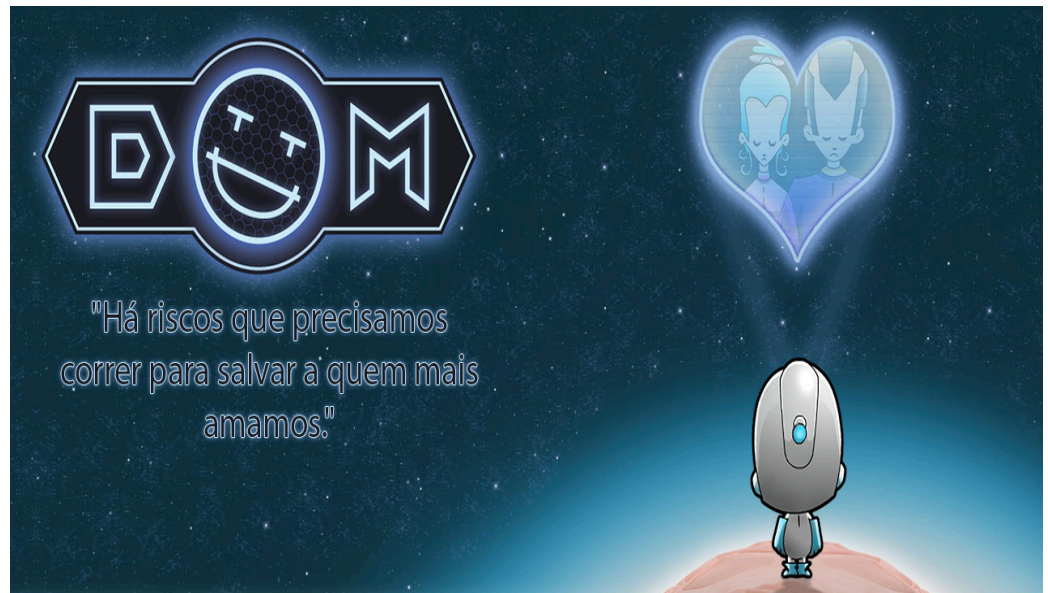

Figura 03: Jogo D.O.M. 
O jogo D.O.M. tem 4 fases (nave, deserto, floresta e caverna) e entre cada fase, o jogador tem acesso a puzzles ou mini-games. Dentro das fases ou nos puzzles, os conceitos matemáticos sobre os coeficientes da função são abordados de forma que o aluno possa identificar que tais variações nos coeficientes geram automaticamente mudanças na posição e formato da parábola.

Um dos momentos onde isso ocorre é na fase da nave, onde para acionar uma porta é necessário clicar em botões que representam os coeficientes de uma parábola e movem esta parábola em um plano cartesiano representado em um dos monitores da nave. Ao conseguiu posicionar a parábola corretamente a porta de um dos compartimento é aberta, como pode ser visto na Figura 04.

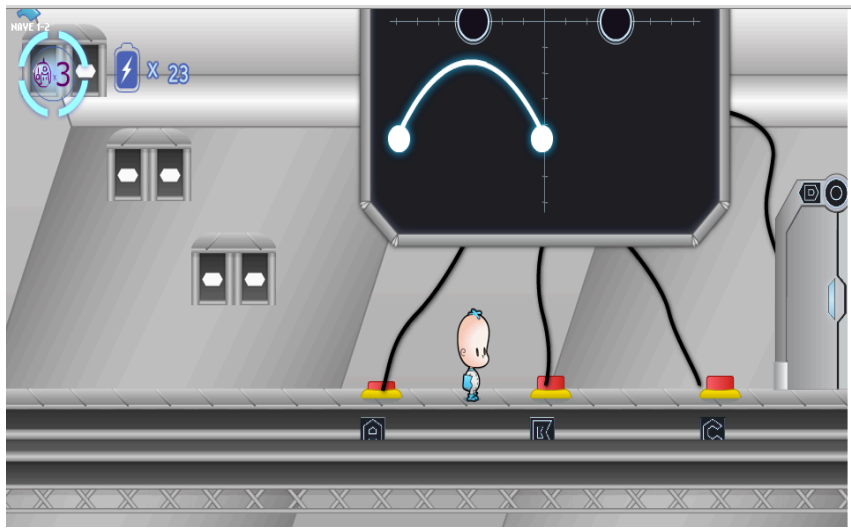

Figura 04: Fase Nave.

A utilização do simulador de funções é outro momento em que o jogador estabelece a relação entre os coeficientes e a parábola (Figuras 05 e 06). A cada clique nos botões que representam os coeficientes, em tempo real o aluno visualiza as modificações que ocorrem na parábola permitindo ao mesmo criar conjecturas sobre a influência de cada coeficiente para a parábola.
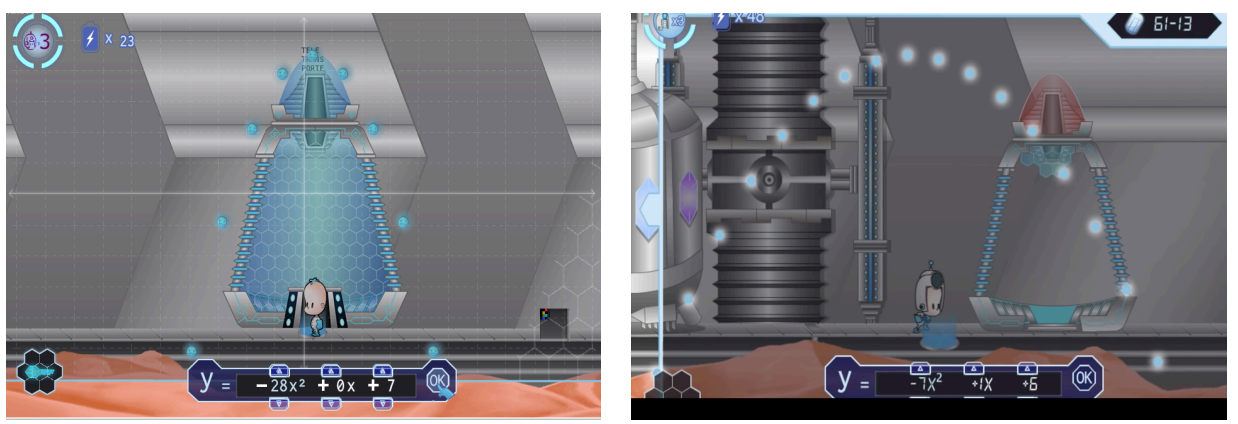

Figura 05: Fase Nave
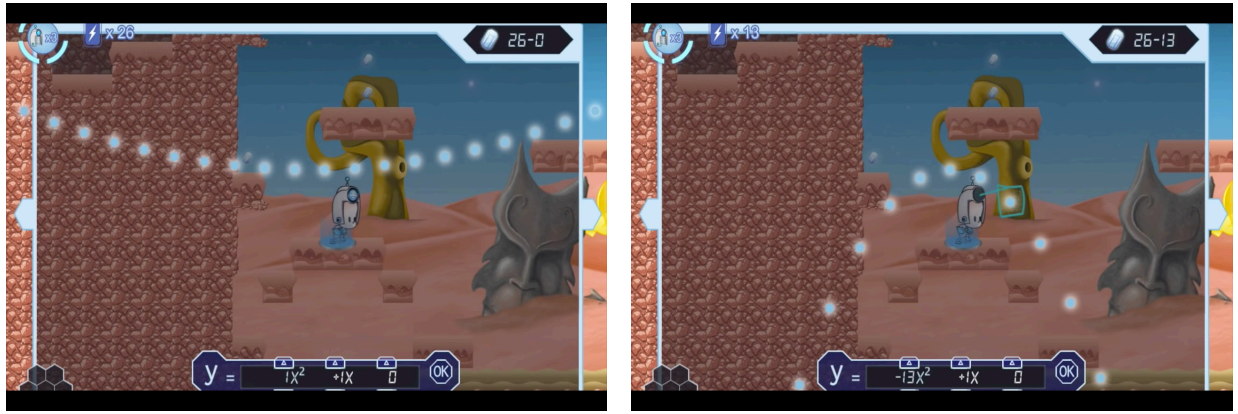

Figura 06: Fase Deserto 
O jogo D.O.M. foi avaliado por 5 profissionais da área de educação, inclusive um professor de matemática, através do Instrumento de Avaliação da Qualidade de Jogos Digitais com Finalidade Educativa (IAQJED) de autoria de (COUTINHO e ALVES, 2016). Este instrumento leva em consideração 3 dimensões: a usabilidade, a experiência do usuário e os princípios de aprendizagem, onde cada dimensão tem 30 pontos.

Tabela 05 - Avaliação do D.O.M.

\begin{tabular}{|c|c|c|c|c|}
\hline & Usabilidade & Experiência & P. Aprendizagem & Total \\
\hline $\begin{array}{c}\text { Média de pontos } \\
\text { dos avaliadores }\end{array}$ & 20,6 & 26,2 & 24,4 & 71,2 \\
\hline
\end{tabular}

Fonte: Autores

Considerando os cinco níveis de qualidade apresentados pelo IAQJED, que são: inadequado (de 1 à 18 pontos), baixa qualidade (de 19 à 36 pontos), qualidade regular (de 37 à 54 pontos), boa qualidade (de 55 à 72 pontos) e excelente qualidade (de 72 à 90 pontos), foi constatado que o jogo D.O.M. apresenta uma boa qualidade para a finalidade educativa.

\section{Considerações}

Como foi sinalizado neste artigo, as avaliações nacionais e internacionais tem evidenciado que a aprendizagem matemática no Brasil vem apresentando problemas.

As pesquisas dos outros países já indicados anteriormente, demonstram as contribuições que os jogos digitais tem trazido para o processo de ensino aprendizagem da matemática e que tal prática pode auxiliar na melhoria dos índices nacionais e internacionais. Os jogos digitais fazem parte do cotidiano dos nossos alunos e precisamos aprender a lidar com eles e utilizar das suas potencialidades, aproximando a escola do universo dos alunos.

Para tanto, o jogo D.O.M. foi desenvolvido com o intuito de contribuir nesta área de pesquisa, sendo um ambiente lúdico e divertido, onde é possível abordar um conteúdo matemático sem ser maçante e desmotivante, desmistificando que a aprendizagem matemática é para poucos.

Atualmente o jogo D.O.M. é a base de uma tese de doutorado que busca criar um modelo de avaliação que possa evidenciar as contribuições deste jogo no processo de ensino aprendizagem das funções quadráticas, subsidiando outras práticas pedagógicas mediadas pelos games, especialmente em relação a matemática. Nossa perspectiva é contribuir para esta área de pesquisa apresentando em futuras publicações dados que demonstrem tais contribuições dos jogo digitais no contexto educacional.

\section{Referências}

ALVES, L. Relações entre os jogos digitais e aprendizagem: delineando percurso, in Educação, Formação \& Tecnologias; vol.1(2); p. 3 - 10, novembro de 2008. 
BRASIL, Orientações curriculares para o ensino médio ; volume 2. Ciências da natureza, matemática e suas tecnologias / Secretaria de Educação Básica. Brasília, 2006.

COUTINHO, I.; ALVES, L. Instrumento de Avaliação da Qualidade de Jogos Digitais com Finalidade Educativa (IAQJED). XXXIX Congresso Brasileiro de Ciências da Comunicação - INTERCOM. São Paulo - SP. 2016.

GEE, J. P. Video Games, Learning, and "Content". In: Miller, Christopher Thomas (org.). Purpose and Potential in Education. Nova York: Springer, 2008.

IDEB, Índice de Desenvolvimento da Educação Básica. Disponível em: http://provabrasil.inep.gov.br/resultados-2015. Acesso em 22 Out. 2016.

MATTAR, J. Games em educação: como os nativos digitais aprendem. São Paulo: Pearson Prentice Hall, 2010.

OLIVEIRA, N. Conceito de função: Uma abordagem do processo ensinoaprendizagem. 1997.

PISA. Programa Internacional de Avaliação de Estudantes. Disponível em http://portal.inep.gov.br/pisa-programa-internacional-de-avaliacao-de-alunos.

Acesso em 22 Out. 2016.

PRENSKY, M. Não me atrapalhe, mãe - Eu estou aprendendo! São Paulo: Phorte, 2010.

ROWLAND, T., O uso de games na matemática por alunos brasileiros Disponível em: http://porvir.org/porpensar/uso-de-games-na-matematica-poralunos-brasileiros/20130905. Acesso em 26 abr 2014

SANTOS, W. D.O.M.: Um Modelo De Game Para A Aprendizagem Das Funções Quadráticas No Ensino Médio. Dissertação PPGMCTI-Senai Cimatec. Salvador. 2014. 